\title{
Thermoelectric Properties of Co-doped ZnO by Incorporating Organic Nanoparticles
}

\author{
Wu Zihua, Xie Huaqing, Wang Yuanyuan, Xing Jiaojiao, Mao Jianhui \\ Shanghai Second Polytechnic University, Shanghai 201209, China
}

\begin{abstract}
Organic-inorganic nanojunction can result in a selective scattering of charge carrier depending on their energy, which leads to a simultaneous increase in Seebeck coefficient $S$ and power factor PF when the Fermi levels of the constituent materials are aligned appropriately. In this work, the nanojunction was employed at the organic-inorganic semiconductor interface of polyparaphenylene (PPP) and $\mathrm{Zn}_{1-x} \mathrm{Co}_{x} \mathrm{O}$ nanoparticles through a sol-gel method. The resulting $\mathrm{Zn}_{0.925} \mathrm{Co}_{0.075} \mathrm{O} / 9 \mathrm{wt} \%$ PPP hybrids exhibit a high power factor due to the largest electrical conductivity and higher Seebeck coefficient. Moreover, organic-inorganic nano-interface effectively reduces the thermal conductivity by interface scattering of phonons. All these effects finally lead to a thermoelectric figure of merit, $Z T$ up to 0.22 in these inorganic-organic nanocomposites, which corresponds to a 5 -fold enhancement compared to that of the $\mathrm{Zn}_{0.925} \mathrm{Co}_{0.075} \mathrm{O}$ matrix. This work demonstrates the effectiveness of nanojunctions and provides a rational route to high performance thermoelectrics in a bulk material.
\end{abstract}

Key words: thermoelectrics; Co-doped $\mathrm{ZnO}$; PPP; nanojunction; sol-gel method

Approximately $90 \%$ of the world's electricity is generated by heat energy, typically operating at $30 \% \sim 40 \%$ efficiency, losing roughly 15 terawatts of power in the form of heat to the environment ${ }^{[1]}$. How to recover this waste heat becomes a subject of great interest. In this regard, thermoelectric (TE) materials attract a lot of attention due to their unique capacity to directly convert heat into electricity. However, the application of TE devices, to date, was severely restricted since the conversion efficiency is lower ${ }^{[2-4]}$. The performance of TE materials was determined by the dimensionless figure-of-merit $Z T$, defined as $Z T=S^{2} \sigma T / \kappa$, where $\sigma$ is the electrical conductivity, $S$ is the Seebeck coefficient ( $\sigma S^{2}$ is referred as power factor), $\kappa$ is the thermal conductivity, and $T$ is the absolute temperature. A high-performance TE material requires a low thermal conductivity to maintain temperature difference, a high electrical conductivity to reduce joule heating, and a large Seebeck coefficient to promote energy conversion of heat to electricity ${ }^{[5,6]}$. But the strong interdependence of these three parameters impose restrictions on improving $Z T$ value ${ }^{[7]}$. Recently, inorganic nano-structured TE materials have improved $Z T$ value by phonon scattering to reduce thermal conductivity without losing of power factor ${ }^{[8]}$, or by energy filtering to independently enhance Seebeck coefficient without greatly suppressing electrical conductivity ${ }^{[9]}$. For example, high $Z T$ values were achieved in P-type BiSbTe $(Z T=1.4)^{[10]}$ and P-type PbTe $(Z T=1.8)^{[11]}$. However, the problems of these inorganic compounds are as follows: (a) the shortage of raw materials; (b) the toxicity of some element; (c) the instability of these compounds under high temperature $^{[12]}$. In such a case, $\mathrm{ZnO}$-based TE material becomes a promising candidate due to its large Seebeck coefficient and high charge mobility ${ }^{[13-15]}$. Moreover, a lot of studies about $\mathrm{ZnO}$ TE materials have been done to enhance $Z T$ value through reducing thermal conductivity, but most of the results are lower $(Z T<0.2)^{[16,17]}$. Therefore, we need to find other methods in order to further improve TE performance.

Received date: March 03, 2017

Foundation item: National Natural Science Foundation of China (51476095, 51590902); Program for Professor of Special Appointment (Eastern Scholar and Young Eastern Scholar, QD2015052) at Shanghai Institutions of Higher Learning

Corresponding author: Xie Huaqing, Ph. D., Professor, Department of Materials Engineering, College of Engineering, Shanghai Second Polytechnic University, Shanghai 201209, P. R. China, Tel: 0086-21-50216301, E-mail: hqxie@sspu.edu.cn 
More recently, an increasing number of researches have demonstrated that organic-inorganic nanojunctions can result in a selective scattering of charge carriers, depending on their energy, which leads to a simultaneous increase in both Seebeck coefficient $S$ and power factor $P F$ when the Fermi levels of the constituent materials are aligned appropriately $^{[18]}$. Furthermore, See et $\mathrm{al}^{[19]}$. fabricated PEDOT-Te hybrid TE materials and gained a better result of $Z T=0.1$ at room temperature. $\mathrm{He}$ et al. ${ }^{[20]}$ prepared poly(3-hexylthiophene)- $\mathrm{Bi}_{2} \mathrm{Te}_{3}$ nanocomposites and enhanced power factor. Inspired by those previous results, we focus on rationally engineering the organic-inorganic interface to improve the Seebeck coefficient and power factor. The organic-inorganic interface was created by mixed conducting polymer nanoparticles into inorganic matrix through sol-gel route. On the other hand, we also expect that the hybridizing of organic and inorganic can lower thermal conductivity due to the drastic mismatch in characteristic vibrational spectra between organic and inorganic moieties.

Among various conducting polymer, polyparaphenylene (PPP) is one of the most widely studied organic semiconductors and possesses excellent chemical stability and electrical property ${ }^{[21,22]}$. Therefore, in this paper, we synthesized a series of $\mathrm{Zn}_{1-x} \mathrm{Co}_{x} \mathrm{O} / \mathrm{PPP}$ powders, and then compressed the powders into bulk pellets through spark plasma sintering (SPS). The microstructure and thermoelectric properties of hybrid samples were investigated in detail. All these effects finally lead to a thermoelectric figure of merit, $Z T$ up to 0.22 in these inorganic-organic nanocomposites, which are orders of magnitude enhancement compared to the pure $\mathrm{Zn}_{1-x} \mathrm{Co}_{x} \mathrm{O}$ matrix.

\section{Experiment}

The PPP was synthesized by polymerization of benzene in the presence of a catalyst, mixture of aluminum chloride $\left(\mathrm{AlCl}_{3}\right)$ and cuprous chloride dihydrous $\left(\mathrm{CuCl}_{2} \cdot 2 \mathrm{H}_{2} \mathrm{O}\right)$. Appropriate amounts of benzene, $\mathrm{AlCl}_{3}-\mathrm{CuCl}_{2} \cdot 2 \mathrm{H}_{2} \mathrm{O}$ were weighed and loaded into a three-necked, round-bottomed flask. The mixture was stirred and heated up to $313 \mathrm{~K}$ for 2 $\mathrm{h}$ in an oil bath, and then cooled to room temperature. After the reaction was complete, the slurry was filtered and washed some times, and dried at $363 \mathrm{~K}$ for $200 \mathrm{~min}$ in a drying oven.

The $\mathrm{Zn}_{1-x} \mathrm{Co}_{x} \mathrm{O} / \mathrm{PPP}$ nanopowder was prepared by a sol-gel process. Appropriate amounts of zinc acetate $\left[\mathrm{Zn}\left(\mathrm{CH}_{3} \mathrm{COO}\right)_{2}\right]$ and cobalt acetate $\left[\mathrm{Co}\left(\mathrm{CH}_{3} \mathrm{COO}\right)_{2}\right]$ (For $\mathrm{Zn}_{0.925} \mathrm{Co}_{0.075} \mathrm{O}$ sample: $6.32 \mathrm{~g}$ of $\mathrm{Zn}\left(\mathrm{CH}_{3} \mathrm{COO}\right)_{2}$ and $0.48 \mathrm{~g}$ of $\left.\mathrm{Co}\left(\mathrm{CH}_{3} \mathrm{COO}\right)_{2}\right)$ were weighed and dissolved in diethylene glycol $\left(\mathrm{C}_{4} \mathrm{H}_{10} \mathrm{O}_{3}\right)$ solution. The proportion of cobalt acetate was adjusted to obtain $\mathrm{Co}$ atomic concentration $x=0$, and 0.075 . The mixture was stirred vigorously and heated to $438 \mathrm{~K}$. The PPP powder then was added into the mixture solution slowly and kept at $438 \mathrm{~K}$ for $2 \mathrm{~h}$. After gelation, rinsing, filtration and drying, the nanocomposites powder was gained. Finally, the sample was annealed at $870 \mathrm{~K}$ for $5 \mathrm{~h}$ in an annealing furnace.

To study the thermoelectric properties, the powder with different content Co and PPP was compressed by spark plasma sintering equipment (SPS-2040). All the samples were sintered at $850 \mathrm{~K}$ under a pressure of $40 \mathrm{MPa}$ in vacuum for $10 \mathrm{~min}$. Then, $2 \mathrm{~mm} \times 2 \mathrm{~mm} \times 10 \mathrm{~mm}$ bars and $\Phi$ $6 \mathrm{~mm} \times 1.5 \mathrm{~mm}$ plates were cut to measure their thermoelectric properties. Both electrical conductivity and Seebeck coefficient were measured simultaneously using ZEM-3 system; the thermal conductivity was calculated from the value of the thermal diffusivity $(\lambda)$, density $(\rho)$ and specific heat $\left(C_{\mathrm{p}}\right)$ using the relationship $\kappa=\lambda \rho C_{\mathrm{p}}$, in which $\lambda$ was measured using a laser flash system (FL-4100). The phase and composition of the products were characterized by X-ray diffraction (XRD) using a Rigaku D/max 2500 diffractometer at a voltage of $40 \mathrm{kV}$ and a current of 200 $\mathrm{mA}$ with $\mathrm{Cu}-\mathrm{K} \alpha$ radiation $(\lambda=0.15406 \mathrm{~nm})$, employing a scanning rate $0.02^{\circ} \mathrm{s}$ in the $2 \theta$ ranging from $30^{\circ}$ to $80^{\circ}$. Their microstructures were investigated by transmission electron microscope (TEM).

\section{Results and Discussion}

The X-ray diffraction patterns of inorganic $\mathrm{Zn}_{1-x} \mathrm{Co}_{x} \mathrm{O}$ samples and $\mathrm{Zn}_{1-x} \mathrm{Co}_{x} \mathrm{O} / \mathrm{PPP}$ hybrids are shown in Fig.1. The diffraction peaks and relative intensities of all patterns match well with the hexagonal wurtzite structure of $\mathrm{ZnO}$ (JCPDS 80-0075), and no extra peaks of impurity phase are observed in the patterns, because Co-doped concentration is less than the solubility and the PPP is an amorphous nature without showing obvious diffraction peaks. Fig.2a shows the TEM micrograph of the $\mathrm{Zn}_{0.925} \mathrm{Co}_{0.075} \mathrm{O} / 9 \mathrm{wt} \%$ PPP sample prepared by spark plasma sintering. It can be seen that many of the white nanoinclusions are embedded in the matrix's surface, and their diameter varies from $5 \mathrm{~nm}$ to 50 $\mathrm{nm}$ except for very few large particles. The energy dispersive spectrum (EDX) analysis of white nanoinclusions exhibits a very strong peak of $\mathrm{C}$ in addition to a small number of $\mathrm{Zn}$ and $\mathrm{O}$. This result indicates that the white nanoinclusions are PPP. While the matrixes exhibit a very strong peak of $\mathrm{Zn}$ and $\mathrm{O}$, and a small amount of $\mathrm{Co}$ $(\mathrm{Zn}: \mathrm{Co}: \mathrm{O}=45.5: 3.7: 51)$. HRTEM image of $\mathrm{Zn}_{0.975} \mathrm{Co}_{0.025} \mathrm{O} /$ $9 w t \%$ PPP (Fig.2b) shows that the lattice spacing of the matrix is $0.522 \mathrm{~nm}$. The results are consistent with the lattice spacing of the (001) plane of $\mathrm{ZnO}$ crystal along the $c$ axis. Above $873 \mathrm{~K}$, carbonization of PPP would take place because the decline of $\mathrm{H} / \mathrm{C}$ ratio was observed. In our experiments, the composite powders were annealed at 870 $\mathrm{K}$ for $5 \mathrm{~h}$ in order to obtain chemical-composition-stable samples. Because the amount of the included PPP is very 


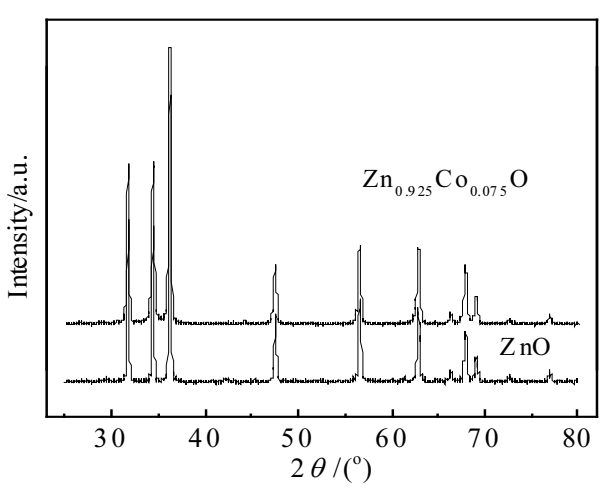

Fig.1 XRD patterns of $\mathrm{Zn}_{1-x} \mathrm{Co}_{x} \mathrm{O}$ samples $(x=0,0.075)$

small and the measurement of $\mathrm{H}$ element in the composite is a nontrivial task, the identification of $\mathrm{H} / \mathrm{C}$ ratio and backbone structure of the annealed PPP is not successful till now. Further studies are needed to clarify the possible effects of PPP carbonization on the thermoelectric properties of the nanocomposites.

The electrical conductivity and Seebeck coefficient of all prepared hybrids are shown in Fig.3a and 3b, respectively. The $\mathrm{Co} / \mathrm{Zn}$ ratio results in variation of electrical conductivity. The electrical conductivity increases with the increasing of Co concentration. Besides, addition of PPP nanoinclusions in $\mathrm{Zn}_{1-x} \mathrm{Co}_{x} \mathrm{O}$ results in an increase in carrier

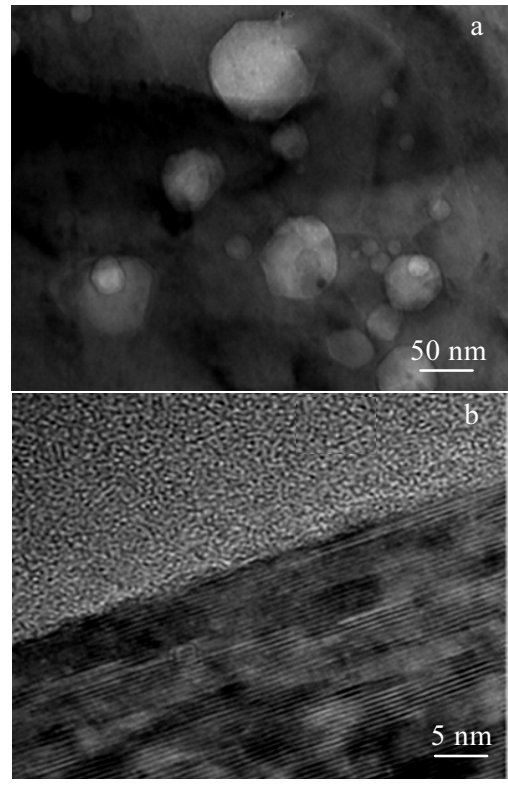

Fig.2 Microstructure images of the $\mathrm{Zn}_{0.975} \mathrm{Co}_{0.025} \mathrm{O} / 9 \mathrm{wt} \%$ PPP sample: (a) TEM image and (b) HRTEM image

concentration and subsequent increase in electrical conductivity ${ }^{[23,24]}$. The carrier concentration of the nanocomposites obtained by the Hall effect is $7.6 \times 10^{18} \cdot \mathrm{cm}^{-3}$,
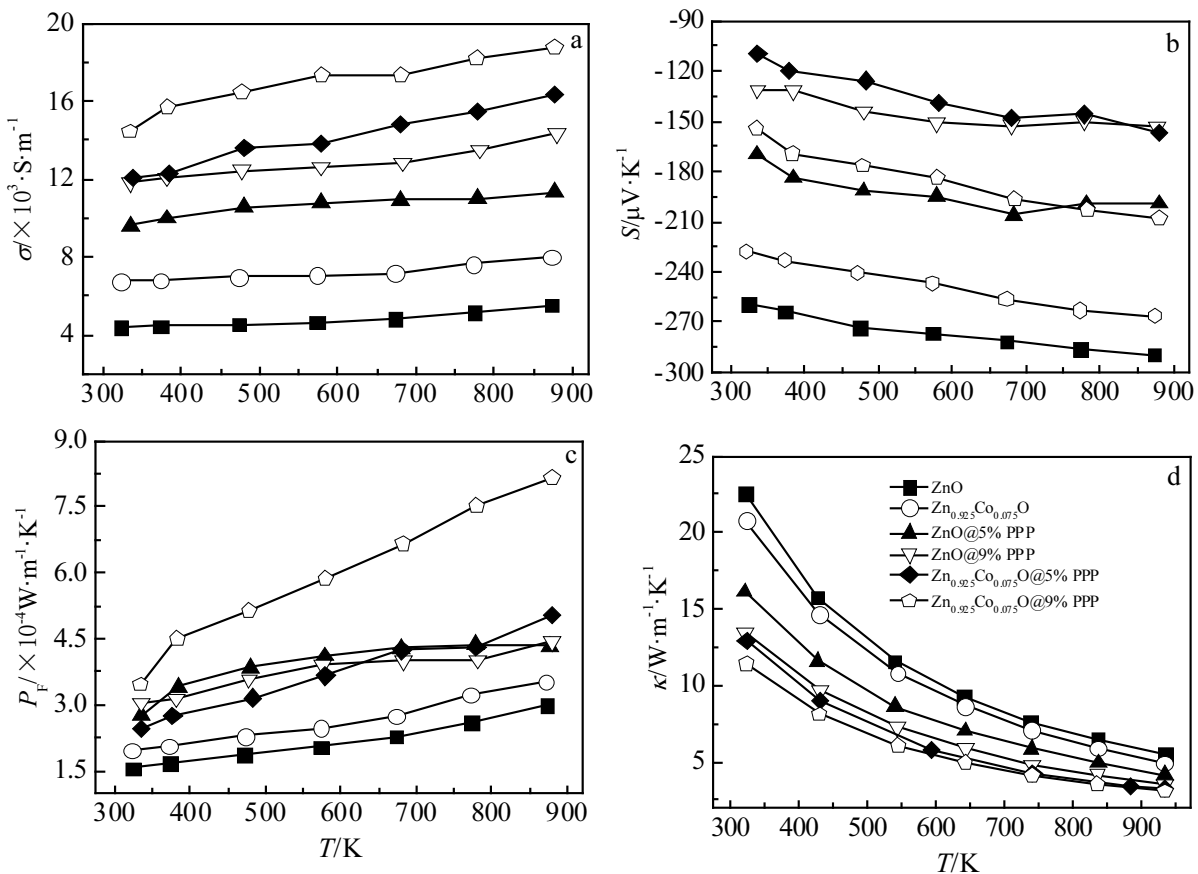

Fig.3 Temperature dependence of thermoelectric transport properties for all the samples: (a) electrical conductivity $(\sigma)$, (b) Seebeck coefficient $(\mathrm{S}),(\mathrm{c})$ power factor $\left(P_{\mathrm{F}}\right)$, and $(\mathrm{d})$ thermal conductivity $(\kappa)$ 
$9.5 \times 10^{18} \cdot \mathrm{cm}^{-3}$ for $\mathrm{Zn}_{0.925} \mathrm{Co}_{0.075} \mathrm{O} / 5 \mathrm{wt} \% \quad$ PPP and $\mathrm{Zn}_{0.925} \mathrm{Co}_{0.075} \mathrm{O} / 9 \mathrm{wt} \% \mathrm{PPP}$, respectively. Generally, there is a decrease in Seebeck coefficient with the inclusion of PPP nanoparticles. However, the tendency is markedly different. For $\mathrm{ZnO} / \mathrm{PPP}$ family of samples, the Seebeck coefficient decreases with the increasing of PPP content; but for $\mathrm{Zn}_{0.925} \mathrm{Co}_{0.075} \mathrm{O} / \mathrm{PPP}$ families of samples, the Seebeck coefficient decreases firstly and then increases. For $\mathrm{Zn}_{0.925} \mathrm{Co}_{0.075} \mathrm{O} / \mathrm{PPP}$ family of samples, the Seebeck coefficient decreases from $-227 \mu \mathrm{V} \cdot \mathrm{K}^{-1}$ for $\mathrm{Zn}_{0.925} \mathrm{Co}_{0.075} \mathrm{O}$ sample to $-110 \mu \mathrm{V} \cdot \mathrm{K}^{-1}$ for $\mathrm{Zn}_{0.925} \mathrm{Co}_{0.075} \mathrm{O} / 5 \mathrm{wt} \%$ PPP sample, and then increases to $-155 \mu \mathrm{V} \cdot \mathrm{K}^{-1}$ for $\mathrm{Zn}_{0.925} \mathrm{Co}_{0.075} \mathrm{O} / 9 \mathrm{wt} \%$ PPP sample at $300 \mathrm{~K}$. The overall effect on the electrical transport is elucidated in Fig.3c, which shows the power factor of all the samples as a function of temperature. The highest power factors are achieved for $\mathrm{Zn}_{0.925} \mathrm{Co}_{0.075} \mathrm{O} / 9 \mathrm{wt} \%$ PPP sample, because they have the largest electrical conductivity and higher Seebeck coefficient. In $\mathrm{Zn}_{0.925} \mathrm{Co}_{0.075} \mathrm{O}$ family of samples, the inclusion of PPP nanoparticles causes an approximate tripling of the electrical conductivity with only $40 \%$ reduction in Seebeck coefficient.

It is of key importance to understand the origin of the enhanced Seebeck coefficient and power factor in $\mathrm{Zn}_{1-x} \mathrm{Co}_{x} \mathrm{O}$ by the mixing of PPP nanoparticles. Mahan and Sofo have already shown that the best efficiency in thermoelectrics energy conversion can be achieved when the electronic transport is through a single energy level ${ }^{[25]}$. Coincidentally, at the organic-inorganic interface unique energy landscapes, materialize as the continuous states in the inorganic are combined with the discrete molecular orbitals in the organic. Organic-inorganic interfaces are ideal in this regard because they can provide charge transport through discrete molecular orbitals. Malen et al. have carefully studied the thermoelectric transport properties in organic-inorganic junctions by simplifying the model. The Seebeck coefficient in organic-inorganic junctions was expressed as ${ }^{[18]}$ :

$$
G_{\mathrm{S}}=\frac{\pi^{2} k_{\mathrm{B}}^{2} T}{3 \mathrm{e}} \frac{2}{E_{\mathrm{f}}-E_{\mathrm{i}}}
$$

where $G_{\mathrm{S}}$ is the junction Seebeck coefficient, $k_{\mathrm{B}}$ is the Boltzmann constant, $E_{\mathrm{f}}$ is the Fermi level of the inorganic, and $E_{\mathrm{i}}$ is the chemical potential of organic molecular orbital. The sign of the Seebeck coefficient discriminates that thermopower will be dominated by the LUMO or HOMO. The negative Seebeck coefficient demonstrated that the LUMO is the dominant transport orbital; oppositely, the positive Seebeck coefficient demonstrated that the HOMO is the dominant transport orbital. In this work, the organic molecular levels are fixed; we mainly adjust the Fermi level of the inorganic by doping Co into $\mathrm{ZnO}$. For PPP, the band gap is $3.4 \mathrm{eV}$ between the LUMO and HOMO, while for
$\mathrm{ZnO}$, the band gap is $3.2 \mathrm{eV}$ between the valence band and conduction band ${ }^{[26-28]}$. The $E_{\mathrm{f}}$ is positioned nearly at the center of the forbidden band for pure $\mathrm{ZnO}$, but the $E_{\mathrm{f}}$ will move up to valence band with the increase of Co-doped concentration. Similarly, the $E_{\mathrm{f}}$ will be close to the LUMO with the increase of Co-doped concentration, which leads to an optimization in Seebeck coefficient for hybrids. Besides, there are some differences between theoretical results and our actual results, since this theory were established under some simple conditions.

The temperature dependence of thermal conductivity for all prepared-samples is shown in Fig.3d. The thermal conductivity of hybrids is lower than that of pure inorganic samples. The increase of PPP nanoparticles concentration results in an almost uniform decrease in thermal conductivity over the entire temperature range. For the $\mathrm{Zn}_{0.925} \mathrm{Co}_{0.075} \mathrm{O}$ family of samples, the thermal conductivity is reduced by $45 \%$ in the $9 \mathrm{wt} \%$ PPP sample at $830 \mathrm{~K}$. The depression of thermal conductivity can be attributed to the following reasons: (1) the significant mismatch in acoustic vibrational spectra between organic polymer PPP and inorganic $\mathrm{Zn}_{1-x} \mathrm{Co}_{x} \mathrm{O}$ matrix ${ }^{[29]}$; (2) the nanosized inclusion PPP, whose diameter approaches to the phonon mean free path (MFP) of inorganic $\mathrm{Zn}_{1-x} \mathrm{Co}_{x} \mathrm{O}$ matrix ${ }^{[30]}$, effectively scatter phonon. Finally, the temperature dependence of the figure-of-merit $(Z T)$ is shown in Fig.4. It is shown that PPP addition helps to improve the $Z T$ value, especially at high temperature. As a result, the highest $Z T$ reaches 0.22 at 870 $\mathrm{K}$ for $\mathrm{Zn}_{0.925} \mathrm{Co}_{0.075} \mathrm{O} / 9 \mathrm{wt} \%$ PPP sample, which is 5-fold higher than $\mathrm{Zn}_{0.925} \mathrm{Co}_{0.075} \mathrm{O}$ matrix.

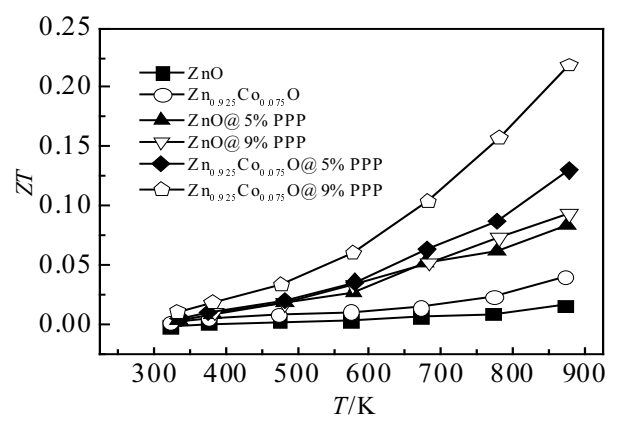

Fig.4 Thermoelectric figure of merit $Z T$ as a function of temperature for all as-prepared samples

\section{Conclusions}

1) Thermoelectric performance can be effectively improved, and the resulting $\mathrm{Zn}_{0.925} \mathrm{Co}_{0.075} \mathrm{O} / 9 \mathrm{wt} \% \mathrm{PPP}$ nanocomposite exhibits a 1.4-fold increase in the power factor, with a great depression in thermal conductivity, thereby leading to a high $Z T$ value of 0.22 at $870 \mathrm{~K}$, which is 5-fold higher than that of $\mathrm{Zn}_{0.925} \mathrm{Co}_{0.075} \mathrm{O}$ matrix $(Z T=0.04)$. 
2) The improved thermoelectric performance is attributed to a possible nanojunction effect at the $\mathrm{Zn}_{1-x} \mathrm{Co}_{x} \mathrm{O}-\mathrm{PPP}$ interface, where discrete molecular orbitals in PPP are combined with the continuum states in $\mathrm{Zn}_{1-x} \mathrm{Co}_{x} \mathrm{O}$, thereby yielding the significantly increase in Seebeck coefficient and power factor.

\section{References}

1 Zhang Q H, Ai X, Wang W J et al. Acta Materialia[J], 2014, 73(4): 37

2 Wang Y K, Chen S P, Fan W H et al. Rare Metal Materials and Engineering[J], 2016, 45(3): 755 (in Chinese)

3 Li E Z, Wang N, He H C et al. Nanoscale Research Letter[J], 2016, 11: 188

4 Du Z L, Cui J L, Zhu T J et al. Rare Metal Materials and Engineering[J], 2014, 43(11): 2623

5 Zhang Q L, Jiang W J, Li J L et al. J Mater Chem A[J], 2013, 1: 12109

$6 \mathrm{Wu}$ H Y, Qin M L, Chu A M et al. Materials Research Bulletin[J], 2016, 75: 78

7 Zheng L J, Zhang B P, Han C G. Rare Metal Materials and Engineering[J], 2015, 44 (12): 3124 (in Chinese)

8 Lee D, Cho K, Choi J et al. Materials Letters[J], 2015, 142: 250

9 Chen D, Zhao Y, Chen Y et al. ACS Appl Mater Interfaces [J], 2015, 7(5): 3224

10 Sommers A D, Truster N L, Napora A C et al. Experimental Thermal and Fluid Science [J], 2016, 75: 25

11 Heremans J P, Jovovic V, Toberer E S et al. Science[J], 2008, 321(5888): 554

12 Choi J, Lee K, Park C R et al. Carbon[J], 2015, 94: 577

13 Koumoto K, Wang Y, Zhang R et al. Annual Review of Materials Research[J], 2010, 40(1): 363
14 Liang X. ACS Appl Mater Interfaces[J], 2015, 7(15): 7927

15 Kim K H, Shim S H, Shim K B et al. Journal of the American Ceramic Society[J], 2005, 88(3): 628

16 Colder H, Guilmeau E, Harnois C et al. Journal of the European Ceramic Society[J], 2011, 31(15): 2957

17 Jood P, Peleckis G, Wang X et al. Journal of Materials Research[J], 2012, 27(17): 2278

18 Malen J A, Yee S K, Majumdar A et al. Chemical Physics Letters [J], 2010, 491(4-6): 109

19 See K C, Feser J P, Chen C E et al. Nano letters[J], 2010, 10 (11): 4664

$20 \mathrm{He}$ M, Ge J, Lin Z et al. Energy \& Environmental Science[J], 2012, 5(8): 8351

21 Draxl A, Majewski J, Vogl P et al. Physical Review B[J], 1995, 51(15): 9668

22 Carstens T, Abedin S Z, Endres F. Chemphyschem: a European Journal of Chemical Physics and Physical Chemistry[J], 2008, 9 (3): 439

$23 \mathrm{Wu}$ Z H, Xie H Q, Wang Y Y et al. Chin Phys Lett [J], 2015, 32(11): 117303

24 Amanatidis I, Kao J Y, Du L Y et al. J Phys Chem C[J], 2015, 119(52): 28728

25 Mahan G D, Sofo J O. Proc Natl Acad Sci[J], 1996, 93: 7436

26 Shacklette L W, Eckhardt H, Chance R R et al. The Journal of Chemical Physics[J], 1980, 73 (8): 4098

27 Lee Y S, Kertesz M. The Journal of Chemical Physics[J], 1988: 88(4): 2609

28 Fang Y J, Sha J, Wang Z L et al. Applied Physics Letters[J], 2011, 98(3): 33103

29 Wang R Y, Segalman R A, Majumdar A. Applied Physics Letters $[\mathrm{J}], 2006$, 89: 96601

30 Baxter J B, Schmuttenmaer C A. The Journal of Physical Chemistry $B[\mathrm{~J}], 2006,110(50): 25229$

\title{
有机纳米颗粒复合 $\mathrm{Co}$ 掺杂 $\mathrm{ZnO}$ 热电性能研究
}

\author{
吴子华, 谢华清, 王元元, 邢姣娇, 毛建辉 \\ (上海第二工业大学, 上海 201209)
}

\begin{abstract}
摘 要: 有机-无机纳米结两端有机材料的离散轨道能级与无机半导体的连续能带差异减小时, 使得纳米结界面具有选择性散射不同能 量载流子的特征，有利于提高赛贝克系数和热电性能。利用溶胶-凝胶法合成了具有有机-无机纳米结结构的聚对苯撑（PPP）纳米复合 $\mathrm{Zn}_{1-x} \mathrm{Co}_{x} \mathrm{O}$ 材料。研究结果表明, 较高电导率和赛贝克系数使 $\mathrm{Zn}_{0.925} \mathrm{Co}_{0.075} \mathrm{O} / 9 \% \mathrm{PPP}$ 呈现较大的功率因子。另外, 有机-无机纳米界面上的 界面散射大大降低了热导率。因而, 合成的纳米复合材料最大 $Z T$ 值达到 0.22 , 是 $Z_{0.925} \mathrm{Co}_{0.075} \mathrm{O}$ 基体材料的 5 倍。这一实验结果表明纳米 结效应是提高块体热电材料热电性能的有效途径。
\end{abstract}

关键词: 热电; $\mathrm{Co}$ 掺杂 $\mathrm{ZnO}$; PPP; 纳米结; 溶胶-凝胶法

作者简介：吴子华，男，1978 年生，博士，副教授，上海第二工业大学工学部材料系，上海 201209, 电话: 021-50216301, E-mail: wuzihua@sspu.edu.cn 